\title{
Effectiveness of Laser Acupoint Therapy and Exercise Program on Oxidative Stress and Antioxidant Response in Mild Essential Hypertensive Patients
}

\author{
Hala M. Hamed, PhD, PT and Mohamed A. Al Maghraby, PhD, PT. \\ Physical Therapy Department, College of Applied Medical Sciences, \\ University of Dammam, Saudi Arabia
}

\begin{abstract}
Background and Purpose; Hypertension is associated with enhanced oxidative stress. Low-level laser therapy (LLLT) has been employed as a treatment for a variety of clinical conditions. Regular physical activity lowers blood pressure and enhances endothelial vasodilator function in hypertensive patients. The main purpose of the study was to measure the levels of serum Malondialdehyde (MDA) and Glutathione peroxidase (GPX) in relation to practicing laser acupuncture therapy and exercise program in mild essential hypertensive patients. Study Type and Design; Interventional, Randomized Control Trial. Subjects and Methods; 45-male patients (40-60 years) with mild essential hypertension were participated in the study. Following baseline measurements, patients were categorized randomly into three homogenous groups; laser therapy, exercise and control. Patients of laser therapy group subjected to a program of laser acupoint therapy to Chinese points for treating hypertension for 4 weeks. Patients of exercise group performed a supervised treadmill exercise program 3 times per week for 4 weeks. Data of pre-and post-intervention measures were collected and statistically analyzed. Results; Comparing postintervention results of laser therapy and control groups, and between exercise and control groups, showed a high statistically significant difference of mean values of $M D A$, systolic blood pressure (SBP), diastolic blood pressure $(D B P)$ and pulse rate $(P R)$, while serum GPX, showed nonsignificant $(P>0.05)$ difference. Conclusions; Short-term (4-week) laser therapy and supervised treadmill exercise programs significantly improved MDA level. There was also a significant reduction in SBP and $D B P$, exhibiting a considerable hypotensive effect. It was found also that laser therapy is more efficient in improving the studied parameters than such improvements documented in exercise program.

Keywords; Essential Hypertension, Oxidative Stress, Malondialdehyde, Glutathione peroxidase, Laser Acupoint, Exercise Program

\section{INTRODUCTION}

Essential hypertension is one of the most prevalent disorders in the adult population worldwide $^{(\mathbf{1})}$ and

cardiovascular and cerebrovascular disease. $^{(\mathbf{2 , 3})}$ The fundamental pathophysiology of essential hypertension is sympathetic overactivity. ${ }^{(4,5)}$
\end{abstract} represents an important risk factor for 
Oxidative stress is the imbalance between the generation of reactive oxygen species (ROS) and the antioxidant defense capacity of the body. ${ }^{(6,7)}$ ROS are derived from reduction of molecular oxygen resulting in formation of superoxide anion, hydrogen peroxide and hydroxyl radical. ${ }^{(8)}$ Under physiological conditions the production of ROS is counterbalanced by a cellular antioxidant defense system that includes enzymes such as superoxide dismutase, catalase and glutathione peroxidase (GPX). These enzymes act as ROS scavengers and convert them into less detrimental compounds. ${ }^{(9)}$ Oxidative stress induced by ROS is a key cause of endothelial cell dysfunction. ${ }^{(10)}$ Vasomotor function is tightly regulated by ROS. At low concentration, ROS regulates vascular tone, proliferation, and cell signaling. However, excessive amount of ROS is associated with the pathogenesis of cardiovascular diseases including hypertension, atherosclerosis, diabetes, and chronic kidney disease. ${ }^{(11)}$

Several lines of evidence suggest that hypertension is associated with enhanced oxidative stress. ${ }^{(7)}$ During hypertension, cells within the vascular wall produce a variety of ROS, including hydrogen peroxide. ${ }^{\text {(3.9.12) }}$ In particular, it has been proposed that superoxide anions might trigger the development of hypertension, by inactivating endothelium-derived nitric oxide, thus impairing its beneficial and protective effects on the vessel wall. In essential hypertension, both the plasma levels of lipid peroxides and the leukocyte production of superoxide anion or hydrogen peroxide were found to be increased, while the levels of antioxidants, were found to be decreased. ${ }^{(13)}$

Pharmacological treatment of hypertension has limitations resulting from drug side effects, costs and patient compliance. ${ }^{(14)}$ Nonpharmacological treatment of hypertension is an important part of the therapeutic strategy. ${ }^{(\mathbf{1 5})}$ Low-level laser therapy (LLLT) is a form of phototherapy which has been employed as a treatment for a variety of clinical conditions, ${ }^{(\mathbf{1 6}, \mathbf{1 7})}$ and is used in many biomedical sciences to promote tissue regeneration. ${ }^{(\mathbf{1 8})}$ Such lasers have also been recommended as an effective alternative to metal needles for the stimulation of acupuncture trigger points; this form of therapy is commonly termed "Laser Acupuncture". (16,19) Laser acupoint therapy has been recently investigated as a physical therapy modality to control blood pressure and improve oxidative balance in essential hypertension. ${ }^{(\mathbf{1 7})}$ There is substantial evidence that regular physical activity lowers blood pressure and enhances endothelial vasodilator function in hypertensive patients. ${ }^{\mathbf{2 0 , 2 1})}$ So that aerobic exercise is considered as an important tool in hypertension management. ${ }^{(22,23)}$

The main aim of the study was to measure the levels of MDA and GPX in relation to practicing laser acupuncture therapy and exercise program in mild essential hypertensive patients. The specific aim of the study was to test the effectiveness of laser acupoint therapy on arterial blood pressure level. 


\section{SUBJECTS \& MATERIAL}

\section{Subjects;}

Forty-five male patients (aged between 40-60 years) with mild essential hypertension $^{(\mathbf{1})}$ (resting blood pressure ranged between 140/90 and $160 / 100 \mathrm{~mm} \mathrm{Hg}$ ) were volunteered to participate in the study. Patients were recruited from Out-patient Clinics of National Heart Institute, Giza, Egypt, during the period of June-September 2010. Patients were non-smokers during the study and were not receiving antihypertensive or antioxidant medications on regular basis. None of the participants changed their physical activity or eating habits during the study.

Patients who met the criteria of inclusion of the study were referred by the treating cardiologist to outpatient physical therapy clinic of the heart institute. Individuals with heart, kidney, thyroid disorders, diabetes, chronic disease or illness, neurological diseases, skin or bleeding disorders, or suffering from any musculoskeletal disorders that might interfere with the study program were not recruited in the study.

Ethical approval for conducting the research was obtained from the Local scientific and ethical research committee of the Heart Institute. All patients provided written informed consent, and the required investigations were conducted to all patients as recommended by the referred physician.

\section{Material;}

- Digital Upper-Arm Blood Pressure Monitor (Model UA-767, Advanced System Technologies Ltd, UK).
- Heart rate monitor (S410, Polar Electro Oy, Kempele, Finland).

- Electronic treadmill (Lode's Instrument B.V, Groningen, Netherlands).

- The Laser Therapy Unit, BTL-5110 Laser, USA.

\section{Methods;}

Evaluative Procedures:

All patients were examined between 8:30 AM and 11:30 AM to minimize the effects of diurnal biological variations. Patients underwent the following evaluative measures at the beginning and at the end of study period (4-weeks);

- Arterial blood pressure and pulse rate (PR) were measured after 10minute of rest with patient in the sitting position by using the digital upper-arm blood pressure monitor.

- Quantitative analysis of serum MDA.

- Serum GPX analysis by using commercial kit provided by Oxis International Inc, Portland USA.

Physical Therapy Procedures:

Following baseline assessments, patients were categorized randomly into three homogenous groups; laser therapy, exercise and control, each group compromised of 15 patients.

Patients of laser group underwent LLLT by using BTL-5110 Laser therapy unit, applied to acupuncture points through pressure contact technique by using infrared laser probe. The parameters of application were; duration of 2 minutes, wave length of $904 \mathrm{~nm}$, frequency of 5000 $\mathrm{Hz}$, an average peak power of $5 \mathrm{~mW}$ and energy density of $2 \mathrm{~J} / \mathrm{cm}^{2}, 3$ times per week for 4 weeks. The points selected for treatment of hypertension 
were LI 4 and LI 11 in the upper arm. $^{\text {(24) }}$

Patients of exercise group were familiarized with the treadmill used and informed about the protocol of the exercise program. They received a supervised moderate treadmill program at $60 \%$ of heart rate reserve, as determined by the heart rate monitor, for 20 minutes, 3 times per week for 4 weeks. ${ }^{\text {(25) }}$

Patients of control group were instructed to perform their usual daily physical activities and were not contacted during the 4-weeks intervention period except for counseling of medical care as recommended by the referred cardiologist, and after 4-weeks, to record post measures.

\section{Statistical Analysis:}

Data of pre- and post-intervention measures were collected and entered into statistical program (SPSS version 16). Descriptive statistics were performed followed by analysis of variance (ANOVA test) to compare the means of parameters of the three groups. Dunnett t (2-sided) test was used to elicit multiple comparisons among the three groups. Paired t-test was used to test the difference between different pairs of groups, and the selected level of significance was 0.05 and a significant level less than 0.01 was considered highly significant.

\section{RESULTS}

Forty-five male patients with mild essential hypertension were categorized randomly into three groups; laser therapy, exercise and control. Table (1) shows nonsignificant $(\mathrm{P}>0.05)$ difference of all studied parameters among the three groups before the intervention.

Table (1): Pre-intervention of mean, standard deviation and test of significance of the studied parameters among laser, exercise and control groups

\begin{tabular}{|l|c|c|c|c|}
\hline \multicolumn{1}{|c|}{ Variables } & Laser Group & Exercise Group & Control Group & ANOVA test \\
\hline MDA, nmol/ml & $10.68 \pm 5.62$ & $12.47 \pm 7.5$ & $11.88 \pm 6.7$ & $\mathrm{P}>0.05$ \\
\hline GPX, ng/ml & $2.04 \pm 0.17$ & $2.01 \pm 0.28$ & $2.06 \pm 0.26$ & $\mathrm{P}>0.05$ \\
\hline $\mathrm{SBP}, \mathbf{m m ~ H g}$ & $156.66 \pm 4.56$ & $153.0 \pm 8.60$ & $154.76 \pm 6.45$ & $\mathrm{P}>0.05$ \\
\hline $\mathrm{DBP}, \mathbf{m m ~ H g}$ & $99.13 \pm 2.07$ & $99.67 \pm 2.28$ & $98.85 \pm 3.43$ & $\mathrm{P}>0.05$ \\
\hline $\mathrm{PR}, \mathbf{b e a t} / \mathbf{m i n}$ & $82.2 \pm 5.85$ & $81.8 \pm 4.8$ & $81.5 \pm 6.95$ & $\mathrm{P}>0.05$ \\
\hline
\end{tabular}

Data are represented as mean and standard deviation, MDA; Malondialdehyde, $\mathbf{n m o l} / \mathbf{m l}$; nanomoles per milliliter, GPX; Glutathione peroxidase, $\mathbf{n g} / \mathbf{m l}$; nanograms per milliliter, SBP; systolic blood pressure, mm Hg; millimeter mercury, DBP; diastolic blood pressure, PR; pulse rate, beat/min; beats per minute, $\mathbf{P}>\mathbf{0 . 0 5}$; statistically nonsignificant.

Table (2) reveals high statistically significant differences $(\mathrm{P}<0.01)$ of all studied parameters among the three groups after the intervention. 
Table (2): Post-intervention of mean, standard deviation and test of significance of the studied parameters among laser, exercise and control groups

\begin{tabular}{|l|c|c|c|c|}
\hline \multicolumn{1}{|c|}{ Variables } & $\begin{array}{c}\text { Laser } \\
\text { Group }\end{array}$ & $\begin{array}{c}\text { Exercise } \\
\text { Group }\end{array}$ & $\begin{array}{c}\text { Control } \\
\text { Group }\end{array}$ & ANOVA test \\
\hline MDA, nmol/ml & $5.55 \pm 2.01$ & $7.67 \pm 2.03$ & $11.35 \pm 7.5$ & $\mathrm{P}<0.01$ \\
\hline GPX, ng/ml & $1.92 \pm 0.34$ & $2.23 \pm 0.40$ & $2.03 \pm 0.22$ & $\mathrm{P}<0.01$ \\
\hline SBP, mm Hg & $139.0 \pm 5.60$ & $142.0 \pm 8.29$ & $153.84 \pm 7.30$ & $\mathrm{P}<0.01$ \\
\hline DBP, mm Hg & $90.02 \pm 3.87$ & $89.33 \pm 4.81$ & $97.62 \pm 2.98$ & $\mathrm{P}<0.01$ \\
\hline PR, beat/min & $76.9 \pm 4.50$ & $76.5 \pm 5.50$ & $80.2 \pm 8.30$ & $\mathrm{P}<0.01$ \\
\hline $\begin{array}{l}\text { Data are represented as mean and standard deviation, MDA; Malondialdehyde, } \\
\text { nmol/ml; nanomoles per milliliter, GPX; Glutathione peroxidase, ng/ml; nanograms per } \\
\text { milliliter, SBP; systolic blood pressure, mm Hg; millimeter mercury, DBP; diastolic } \\
\text { blood pressure, PR; pulse rate, beat/min; beats per minute, P<0.01; highly significant. }\end{array}$ \\
\hline
\end{tabular}

Table 3 shows multiple comparisons of the mean studied parameters using Dunnett $t$ test. Posthoc test (Dunnett $t$ test) was used to elicit differences between the significant parameters, which showed significant differences. Multiple comparisons were used to identify significant differences between each pair of the three groups. Comparing post-intervention results between laser therapy and control groups, and between exercise and control groups showed a high statistical significant difference $(\mathrm{P}<0.01)$ for all parameters except of GPX, showed nonsignificant $(\mathrm{P}>0.05)$ difference.

Table (3) Multiple paired comparisons of the mean studied parameters among laser, exercise and control groups, post-intervention

\begin{tabular}{|c|c|c|c|}
\hline Dependent Variables & \multicolumn{2}{|c|}{ Groups` } & Significance \\
\hline \multirow{2}{*}{ MDA, nmol/ml } & 1 & 3 & $\mathrm{P}<0.01 *$ \\
\hline & 2 & 3 & $\mathrm{P}<0.01 *$ \\
\hline \multirow{2}{*}{ GPX, ng/ml } & 1 & 3 & $\mathrm{P}>0.05$ \\
\hline & 2 & 3 & $\mathrm{P}>0.05$ \\
\hline \multirow{2}{*}{ SBP, mm Hg } & 1 & 3 & $\mathrm{P}<0.01 *$ \\
\hline & 2 & 3 & $\mathrm{P}<0.01 *$ \\
\hline \multirow{2}{*}{ DBP, $\mathbf{m m} \mathbf{H g}$} & 1 & 3 & $\mathrm{P}<0.01^{*}$ \\
\hline & 2 & 3 & $\mathrm{P}<0.01^{*}$ \\
\hline \multirow{2}{*}{$\mathrm{PR}$, beat/min } & 1 & 3 & $\mathrm{P}<0.01^{*}$ \\
\hline & 2 & 3 & $\mathrm{P}<0.01 *$ \\
\hline \multicolumn{4}{|c|}{$\begin{array}{l}\mathbf{\bullet} \mathbf{1}=\text { Laser therapy group, } \mathbf{2}=\text { Exercise Group, } \mathbf{3}=\text { Control Group. } \\
\text { MDA; Malondialdehyde, } \mathbf{n m o l} / \mathbf{m l} \text {; nanomoles per milliliter, GPX; Glutathione } \\
\text { peroxidase, ng/ml; nanograms per milliliter, SBP; systolic blood pressure, } \mathbf{m m ~ H g ;} \text {; } \\
\text { millimeter mercury, DBP; diastolic blood pressure, PR; pulse rate, beat/min; beats } \\
\text { per minute. } \\
\mathbf{P}<\mathbf{0 . 0 1} \text {; highly significant } \mathbf{P}>\mathbf{0 . 0 5} \text {; nonsignificant. }\end{array}$} \\
\hline
\end{tabular}


On comparing pre- and postintervention values of resting serum MDA among the three group, table (4) shows statistically significant reduction in both laser and exercise groups with the mean difference of 5.13 and $-4.80 \mathrm{nmol} / \mathrm{ml}$ respectively with the favor of Laser group, while control group showed nonsignificant $(>0.05)$ reduction. Figure (1)

Table (4): Pre- and post-intervention mean values of resting serum MDA in $\mathrm{nmol} / \mathrm{ml}$ for patients of three groups

\begin{tabular}{c|cccc}
\hline Groups & $\begin{array}{c}\text { Pre- } \\
\text { intervention }\end{array}$ & $\begin{array}{c}\text { Post- } \\
\text { intervention }\end{array}$ & $\begin{array}{c}\text { Mean } \\
\text { Difference }\end{array}$ & P-value \\
\hline Laser Group & $10.68 \pm 5.62$ & $5.55 \pm 2.01$ & -5.13 & $<0.01$ \\
Exercise Group & $12.47 \pm 7.5$ & $7.67 \pm 2.03$ & -4.80 & $<0.05$ \\
Control Group & $11.88 \pm 6.7$ & $11.35 \pm 7.5$ & -0.53 & $>0.05$ \\
\hline
\end{tabular}

Data are expressed as mean and standard deviation

$\mathrm{P}<0.01$; highly significant, $\mathrm{P}<0.05$; significant, $\mathrm{P}>0.05$; nonsignificant

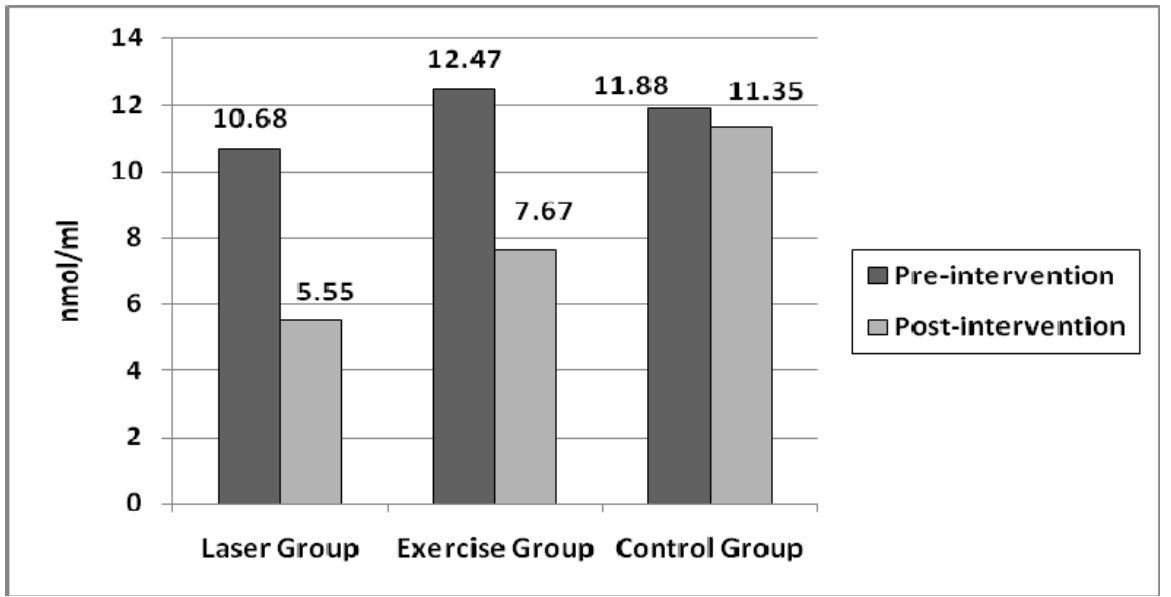

Figure (1): Pre- and post-intervention mean values of resting serum MDA in $\mathrm{nmol} / \mathrm{ml}$ for patients of three groups

On comparing pre- and postintervention values of resting GPX among the three group, table (5) shows a statistically significant reduction $(-0.12)$ in laser group, significant increase $(-0.22)$ in exercise group, while control group showed nonsignificant $(>0.05)$ reduction. Figure (2) 
Table (5): Pre- and post-intervention mean values of resting GPX in $\mathrm{ng} / \mathrm{ml}$ for patients of three groups

\begin{tabular}{c|cccc}
\hline Groups & $\begin{array}{c}\text { Pre- } \\
\text { intervention }\end{array}$ & $\begin{array}{c}\text { Post- } \\
\text { intervention }\end{array}$ & $\begin{array}{c}\text { Mean } \\
\text { Difference }\end{array}$ & P-value \\
\hline Laser Group & $2.04 \pm 0.17$ & $1.92 \pm 0.34$ & -0.12 & $<0.05$ \\
Exercise Group & $2.01 \pm 0.28$ & $2.23 \pm 0.40$ & 0.22 & $<0.05$ \\
Control Group & $2.06 \pm 0.26$ & $2.03 \pm 0.22$ & -0.03 & $>0.05$ \\
\hline
\end{tabular}

Data are expressed as mean and standard deviation

$\mathrm{P}<0.01$; highly significant, $\mathrm{P}<0.05$; significant, $\mathrm{P}>0.05$; nonsignificant

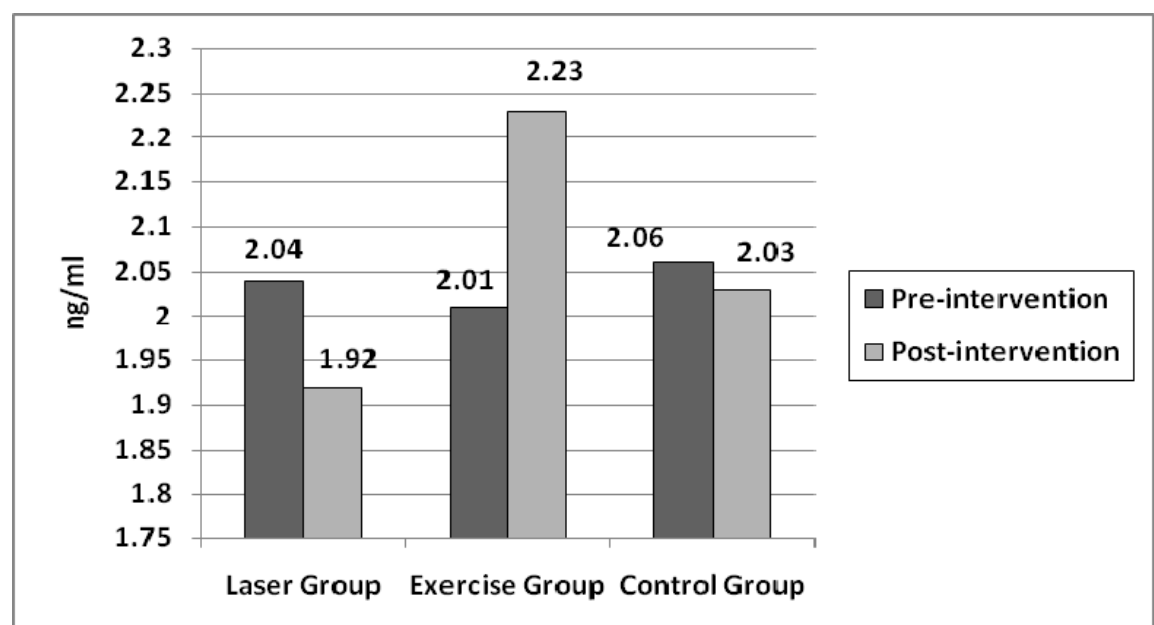

Figure (2): Pre- and post-intervention mean values of resting GPX in $\mathrm{ng} / \mathrm{ml}$ for patients of three groups

On comparing pre- and postintervention values of resting SBP among the three group, table (6) shows statistically significant reduction in both laser and exercise groups with the mean reduction of -
17.66 and $-11.0 \mathrm{~mm} \mathrm{Hg}$ respectively with a much better improvement in Laser group, while control group showed nonsignificant $(>0.05)$ reduction. Figure (3) 
Table (6): Pre- and post-intervention mean values of resting SBP, in $\mathrm{mm} \mathrm{Hg}$, for patients of three groups

\begin{tabular}{c|cccc}
\hline Groups & Pre-intervention & $\begin{array}{c}\text { Post- } \\
\text { intervention }\end{array}$ & $\begin{array}{c}\text { Mean } \\
\text { Difference }\end{array}$ & P-value \\
\hline Laser Group & $156.66 \pm 4.56$ & $139.0 \pm 5.60$ & -17.66 & $<0.01$ \\
Exercise Group & $153.0 \pm 8.60$ & $142.0 \pm 8.29$ & -11.0 & $<0.01$ \\
Control Group & $154.76 \pm 6.45$ & $153.84 \pm 7.30$ & -0.92 & $>0.05$ \\
\hline
\end{tabular}

Data are expressed as mean and standard deviation

$\mathrm{P}<0.01$; highly significant, $\mathrm{P}<0.05$; significant, $\mathrm{P}>0.05$; nonsignificant

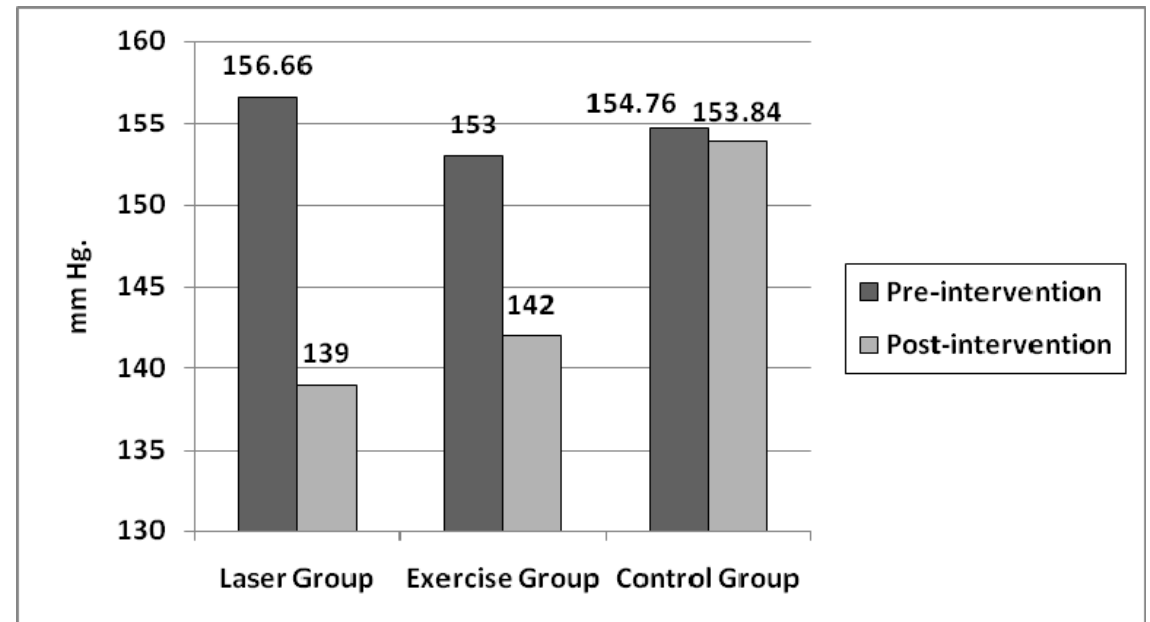

Figure (3): Pre- and post-intervention mean values of resting SBP, in $\mathrm{mm} \mathrm{Hg}$, for patients of three groups

On comparing pre- and postintervention values of resting DBP among the three group, table (7) shows statistically significant reduction in both laser and exercise groups with the mean difference of -
9.11 and $-10.34 \mathrm{~mm} \mathrm{Hg}$ respectively with the greater reduction for the exercise group, while control group showed nonsignificant $(>0.05)$ reduction. Figure (4) 
Table (7): Pre- and post-intervention mean values of resting DBP, in $\mathrm{mm} \mathrm{Hg}$, for patients of three groups

\begin{tabular}{c|cccc}
\hline Groups & $\begin{array}{c}\text { Pre- } \\
\text { intervention }\end{array}$ & $\begin{array}{c}\text { Post- } \\
\text { intervention }\end{array}$ & $\begin{array}{c}\text { Mean } \\
\text { Difference }\end{array}$ & P-value \\
\hline Laser Group & $99.13 \pm 2.07$ & $90.02 \pm 3.87$ & -9.11 & $<0.01$ \\
Exercise Group & $99.67 \pm 2.28$ & $89.33 \pm 4.81$ & -10.34 & $<0.01$ \\
Control Group & $98.85 \pm 3.43$ & $97.62 \pm 2.98$ & -1.23 & $>0.05$ \\
\hline
\end{tabular}

Data are expressed as mean and standard deviation

$\mathrm{P}<0.01$; highly significant, $\mathrm{P}<0.05$; significant, $\mathrm{P}>0.05$; nonsignificant

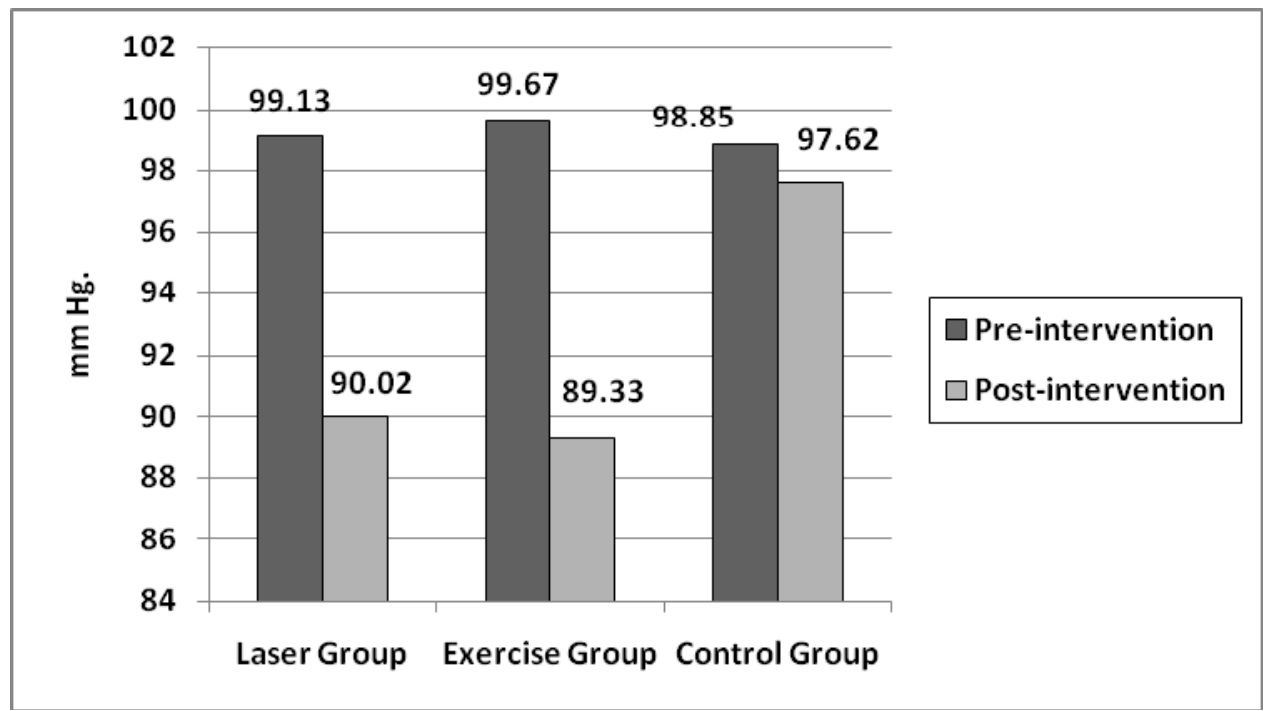

Figure (4): Pre- and post-intervention mean values of resting DBP, in $\mathrm{mm} \mathrm{Hg}$, for patients of three groups

On comparing pre- and postintervention values of resting $\mathrm{PR}$ among the three group, table (8) shows highly significant reduction in both laser and exercise groups with the mean difference of -5.3 and -5.3 $\mathrm{mm} \mathrm{Hg}$ respectively, while control group showed nonsignificant $(>0.05)$ reduction. Figure (5) 
Table (8): Pre- and post-intervention mean values of resting PR, beat $/ \mathrm{min}$, for patients of three groups

\begin{tabular}{c|cccc}
\hline Groups & $\begin{array}{c}\text { Pre- } \\
\text { intervention }\end{array}$ & $\begin{array}{c}\text { Post- } \\
\text { intervention }\end{array}$ & $\begin{array}{c}\text { Mean } \\
\text { Difference }\end{array}$ & $\begin{array}{c}\text { P- } \\
\text { value }\end{array}$ \\
\hline Laser Group & $82.2 \pm 5.85$ & $76.9 \pm 4.50$ & -5.3 & $<0.01$ \\
Exercise Group & $81.8 \pm 4.8$ & $76.5 \pm 5.50$ & -5.3 & $<0.01$ \\
Control Group & $81.5 \pm 6.95$ & $80.2 \pm 8.30$ & -1.3 & $>0.05$ \\
\hline
\end{tabular}

Data are expressed as mean and standard deviation

$\mathrm{P}<0.01$; highly significant, $\mathrm{P}<0.05$; significant, $\mathrm{P}>0.05$; nonsignificant

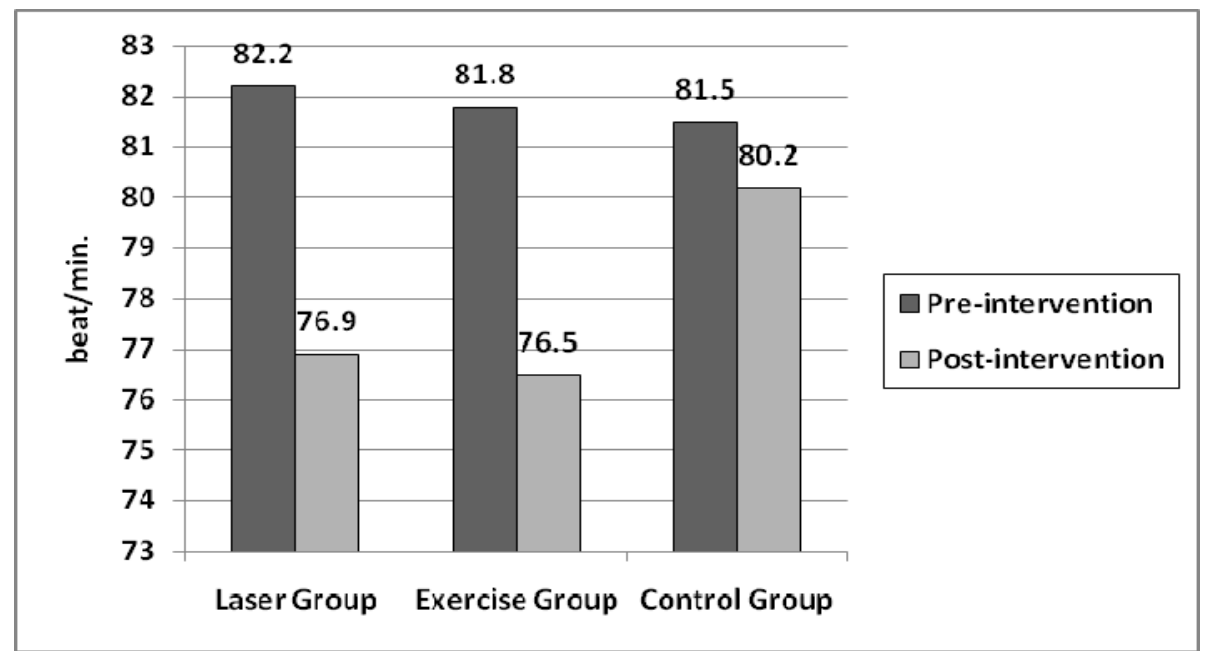

Figure (5): Pre- and post-intervention mean values of resting PR, beat/min, for patients of three groups

On comparing post-intervention records of resting serums; MDA and GPX among the three groups, figure (7) shows that the mean values of MDA of laser therapy group showed the most significant reduction $(5.55$ $\mathrm{nmol} / \mathrm{ml}$ ) compared with exercise group $(7.67 \mathrm{nmol} / \mathrm{ml})$ and control group $(11.35 \mathrm{nmol} / \mathrm{ml})$. While on comparing post-intervention mean values of GPX among the three groups, figure (7) shows nonsignificant differences. 


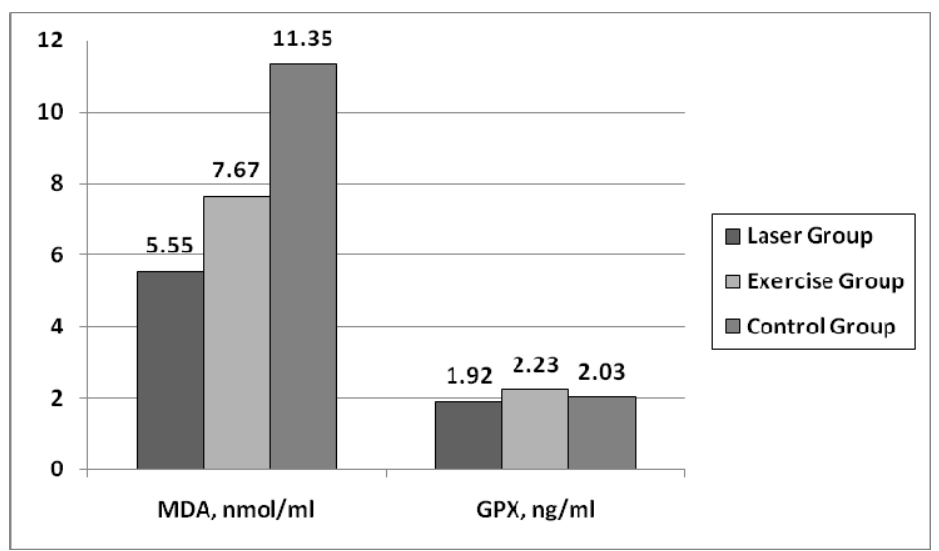

Figure (7): Post-intervention mean values of resting serum; MDA and GPX among the three groups

On comparing post-intervention records of resting SBP among the three groups, figure (8) shows that the mean values of laser therapy group showed the most significant reduction (139 $\mathrm{mm} \mathrm{Hg}$ ) compared with exercise group (142 $\mathrm{mm} \mathrm{Hg}$ ) and control group $(153.84 \mathrm{~mm} \mathrm{Hg})$. While on comparing post-intervention records of resting DBP and resting PR among the three groups, figure (8) shows nonsignificant differences.

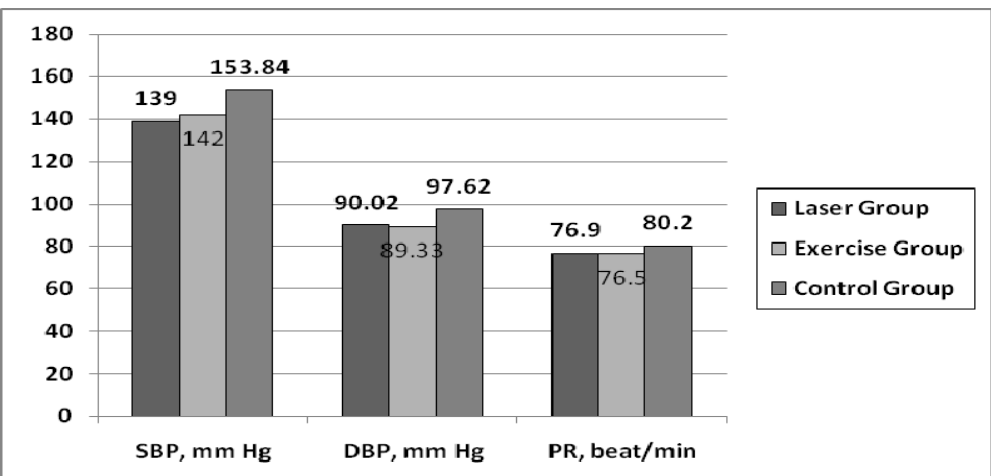

Figure (8): Post-intervention mean values of resting SBP, DBP and PR among the three groups

\section{DISCUSSION}

Hypertensive patients are exposed to apparent oxidant stress. ${ }^{(26)}$ It is caused by imbalance between adaptive antioxidant defensive status and activity of free radical processes. ${ }^{(6)}$ Lowering blood pressure and also reducing lipid peroxidation and enhancement of antioxidant enzymes activity must be required in 
treatment of hypertension. ${ }^{(13,27)}$ Special attention is focused on those with mild to moderate hypertension as they constitute the majority of all hypertensive patients. $^{(5)}$ The non pharmacological treatment is advocated such as exercise ${ }^{(\mathbf{1 2 , 2 1 , 2 3})}$ and also $\operatorname{LLLT}^{(\mathbf{1 6 - 1 9 , 2 8 , 2 9 )}}$ that has been suggested to be a beneficial noninvasive antihypertensive agent.

The statistical analysis of data of laser therapy group after the application of LLLT showed a significant reduction of both resting serum MDA and GPX by -5.13 and 0.12 respectively. This reduction reflects reduced serum lipid peroxidation and reduction of release of ROS from different sites of vascular system at the level of respiratory chain or an increase of antioxidant enzymes. These results agreed with Silveira et al ${ }^{(18)}$ who claimed that LLLT decreases the release of ROS via an action on the Nicotinamide adenine dinucleotide phosphate (NADPH) oxidase system in mitochondria or enhancing the activity of respiratory chain enzyme and cytochrome oxidase. Also, Velizhanina et al (28) reported that patients with angina pectoris who received LLLT for a month reduced their plasma MDA. In addition, Zhang et al ${ }^{(17)}$ reported that infrared laser irradiation contributes to correction of the elevated level of hydro peroxidase and MDA with increased level of superoxide dismutase in the brain. Again, Albertini et $\mathrm{al}^{(\mathbf{3 0})}$ postulated that activation of an enzyme or induction of its synthesis requires only a few photons, once this enzyme activated it can catalyze a cascade of reactions inside the living cell.
The laser group showed also a significant reduction of resting SBP, DBP and PR, which was supported by Velizhanina et al ${ }^{\mathbf{( 2 8 )}}$ who reported in a placebo-controlled study that an antihypertensive activity in relation to LLLT was evaluated in 52 males with essential hypertension stage $I$ as monotherapy of 10 daily procedures. This treatment significantly lowered systolic and diastolic blood pressures.

In this present study, application of exercise program in the form of treadmill training in the exercise group showed a statistical significant reduction in resting serum MDA and a significant increase in serum GPX. These results were supported by Nojimaa et al ${ }^{(31)}$ who reported that moderate-intensity aerobic exercise training over 12 months reduced oxidative stress and improved glycemic control in patients with type 2 diabetes mellitus.

On the other hand, the study documented a significant reduction in both mean resting SBP and DBP values, accompanied by lowering of resting PR in both laser therapy and exercise groups. These changes may be related to attenuation of peripheral resistance induced by laser treatment. ${ }^{(32)}$ Reduction in systemic vascular resistance is due to exerciseinduced sympatholytic vasodilatation in skeletal muscle. ${ }^{(11,32)}$ In addition, Ciolac et al (23) showed that just a single bout of dynamic exercise can decrease BP below basal levels in hypertensive subjects, and that this hypotensive effect remains for several hours after the exercise.

However application of laser therapy in first group induced the most significant effect. This was 
agreed with Lee et al (33) who indicated a potent dilatation in peripheral arterioles treated by laser which lead to marked increase in arterial blood flow. Also, Xiong et al (15) demonstrated a relaxation of vascular smooth muscle cell mediated via release of endothelium derived nitric oxide from arteries irradiated by visible light laser. These results coincide with Hwang et al ${ }^{(34)}$ who conducted a placebo controlled study concerned with antihypertensive activity in relation to LLLT and favored its clear reduction of peripheral vascular resistance.

Several studies have been demonstrated the effects of LLLT on inflammation and tissue repair. ${ }^{(19,30)}$ Data from randomized, controlled trials indicated that increasing aerobic physical activity could be effective for reducing chronic inflammation. ${ }^{(35)}$ Also exercise training-induced improvements in inflammatory status may result from the modulation of intracellular signaling pathways and cellular function that are mediated by nitric oxide and ROS. ${ }^{(11,36)}$

\section{Conclusion}

The present study demonstrated that short-term (4-week) laser therapy and supervised treadmill exercise program significantly improved MDA level. The main findings of this study were the significant reduction in resting SBP and DBP exhibiting a considerable hypotensive effect. It was found also that laser therapy is more efficient in improving the studied parameters than such improvements found in exercise program group. It was also suggested that a combination therapy of both laser therapy and exercise program for those patients will produce more reduction of blood pressure as well as reducing the daily requirements of antihypertensive drugs with their possible associated long-term side effects.

\section{Acknowledgements:}

This study was supported by National Heart Institute, Giza, Egypt and the authors would like to thank Dr. Mohamed Mohi, consultant of cardiology, for his support and help in the selection of patients and Dr. Mustafa Husain, consultant of cardiac rehabilitation, for the allowance to use cardiac facilities in the physical therapy department.

\section{REFERENCES}

1. Turnbull F, Kengne AP, MacMahon S. Blood Pressure and Cardiovascular Disease: Tracing the Steps from Framingham. Prog Cardiovasc Dis 2010; 53: 39-44.

2. Tjugen TB, Flaa A, Kjeldsen SE. High Heart Rate as Predictor of Essential Hypertension: The Hyperkinetic State, Evidence of Prediction of Hypertension, and Hemodynamic Transition to Full Hypertension. Prog Cardiovasc Dis 2009; 52: 20-25.

3. Ardanaz N, Yang X, Cifuentes ME, Haurani MJ, et al. Lack of Glutathione Peroxidase 1 Accelerates Cardiac-Specific Hypertrophy and Dysfunction in Angiotensin II Hypertension. Hypertension 2010; 55: 116-123.

4. Pal GK, Pal P, Nanda N, Amudharaj D, et al. Spectral Analysis of Heart Rate Variability (HRV) may predict the Future Development of 
Essential Hypertension. Med Hypotheses 2009; 72: 183-185.

5. Chien KL, Hsu HC, Su TC, Chang WT, et al. Prediction Models for the Risk of new-onset Hypertension in Ethnic Chinese in Taiwan. J Hum Hypertens 2010; 63: 1-10.

6. Pepe H, Balci S, Revan S, Akalin PP, et al. Comparison of Oxidative Stress and Antioxidant Capacity Before and After Running Exercises in Both Sexes. Gender Med 2009; 6(4): 587-595.

7. Bloomer RJ and FisherWellman KH. Blood Oxidative Stress Biomarkers: Influence of Sex, Training Status, and Dietary Intake. Gender Med 2008; 5(3): 218-228.

8. Florea SM, Blatter LA. The Effect of Oxidative Stress on $\mathrm{Ca}^{2+}$ release and Capacitative $\mathrm{Ca}^{2+}$ entry in Vascular Endothelial Cells. Cell Calcium 2008; 43: 405-415.

9. Chrissobolis $\mathrm{S}$, Didion SP, Kinzenbaw DA, Schrader LI, et al. Glutathione Peroxidase-1 Plays a Major Role in Protecting Against Angiotensin II-Induced Vascular Dysfunction. Hypertension 2008; 51: 872-877.

10. Slodzinski MK, Aon MA, O'Rourke B. Glutathione Oxidation as a Trigger of Mitochondrial Depolarization and Oscillation in Intact Hearts. J Mol Cell Cardiol 2008; 45: 650-660.

11. Yang HC, van Breemen $C$, Chung AW. Vasomotor Dysfunction in the Thoracic Aorta of Marfan Syndrome is associated with Accumulation of Oxidative Stress. Vascular Pharmacology 2010; 52: 37-45.
12. Deley G, Picard G, Taylor JA. Arterial Baroreflex Control of Cardiac Vagal Outflow in Older Individuals Can Be Enhanced by Aerobic Exercise Training. Hypertension 2009; 53; 826-832.

13. Santangelo L, Cigliano L, Montefusco A, Spagnuolo MS, et al. Evaluation of the Antioxidant Response in the Plasma of Healthy or Hypertensive Subjects after Short-term Exercise. J Hum Hypertens 2003; 17: 791-798.

14. Flachskampf FA, Gallasch J, Gefeller O, Gan J, et al. Randomized Trial of Acupuncture to Lower Blood Pressure. Circulation 2007; 115: 3121-3129.

15. Xiong $X$, You $C$, Feng $Q$, Yin $T$, et al. Pulse Width Modulation Electro-acupuncture on Cardiovascular Remodeling and Plasma Nitric Oxide in Spontaneously Hypertensive Rats. eCAM June 4, 2010; 1-6.

16. Baxter GD, Bleakley C, McDonough S. Clinical Effectiveness of Laser Acupuncture: A Systematic Review. J Acupunct Meridian Stud 2008; 1(2): 65-82.

17. Zhang J, Marquina N, Oxinos G, Saud A, et al. Effect of Laser Acupoint Treatment on Blood Pressure and Body Weight. Journal of Chiropractic Medicine 2008; 7: 134-139.

18. Silveira PC, da Silva LA, Fraga DB, Freitas TP, et al. Evaluation of Mitochondrial Respiratory Chain Activity in Muscle Healing by Low-level Laser Therapy. J Photoch Photobio B 2009; 95: 89-92. 
19. Pereira MC, de Pinho CB, Medrado AR, Andrade $\mathrm{ZA}$, et al. Influence of $670 \mathrm{~nm}$ Lowlevel Laser Lherapy on Mast Cells and Vascular Response of Cutaneous Injuries. J Photoch Photobio B 2010; 98: 188-192.

20. Palatini $P$, Visentin $P$, Dorigatti F, Guarnieri C, et al. Regular Physical Activity Prevents Development of Left Ventricular Hypertrophy in Hypertension. Eur Heart J 2009; 30: 225-232.

21. de Almeida WS, Lima LC, da Cunha RR, Simoes HG, et al. Post-exercise Blood Pressure Responses to Cycle and Armcranking. Sci Sport 2010; 25: 7480.

22. Cornelissen VA and Fagard RH. Effects of Endurance Training on Blood Pressure, Blood Pressure-Regulating Mechanisms, and Cardiovascular Risk Factors. Hypertension 2005; 46: 667-675.

23. Ciolac EG, Guimaraes GV, D'Avila VM, Bortolotto LA, et al. Acute Effects of Continuous and Interval Aerobic Exercise on 24-h Ambulatory Blood Pressure in Long-term Treated Hypertensive Patients. Int J Cardiol 2009; 133: 381-387.

24. Zhang J, Ngb D, Saub A. Effects of Electrical Stimulation of Acupuncture Points on Blood Pressure. Journal of Chiropractic Medicine 2009; 8: 9-14.

25. Sharman JE, Stowasser $M$. Australian Association for Exercise and Sports Science Position Statement on Exercise and Hypertension. Journal of Science and Medicine in Sport 2009; 12: 252-257.
26. Williams JB, Roberts SP, Elekonich MM. Age and Natural Metabolically-Intensive Behavior Affect Oxidative Stress and Antioxidant Mechanisms. Exp Gerontol 2008; 43: 538-549.

27. Blacher J, Evans A, Arveiler D, Amouyel P, et al. Residual Cardiovascular Risk in Treated Hypertension and Hyperlipidaemia: the PRIME Study. J Hum Hypertens 2010; 24: 19-26.

28. Velizhanina IA, Gapon LI, Shabalina MS, Kamalova NN. Efficiency of Low-intensity Laser Radiation in Essential Hypertension. Klin Med (Mosk) 2001; 79 (1): 41-44.

29. Macklin EA, Wayne PM, Kalish LA, Valaskatgis P, et al. Stop Hypertension with the Acupuncture Research Program (SHARP). Results of a Randomized Controlled Clinical Trial. Hypertension 2006; 48: 838-845.

30. Albertini $\mathbf{R}$, Villaverde $\mathbf{A B}$, Aimbire F, Salgado MA, et al. Anti-inflammatory Effects of Low-level laser therapy (LLLT) with two Different Red Wavelengths (660 nm and 684 $\mathrm{nm}$ ) in Carrageenan-induced Rat Paw Edema. J Photoch Photobio B 2007; 89: 50-55.

31. Nojimaa $H$, Watanabea $H$, Yamanea K, Kitaharaa Y, et al. Effect of Aerobic Exercise Training on Oxidative Stress in Patients with Type 2 Diabetes Mellitus. Metabolism 2008; 57: 170-176.

32. Hogan TS. Exercise-induced Reduction in Systemic Vascular Resistance: A Covert Killer and an Unrecognized Resuscitation 
Challenge? Med Hypotheses 2009; 73: 479-484.

33. Lee S, Lee MS, Choi J, Lee S, Jeong S, Ernst E. Acupuncture and Heart Rate Variability: A Systematic Review. Autonomic Neuroscience: Basic and Clinical 2010; 155: 5-13.

34. Hwang HS, Kim YS, Ryu YH, Lee JE, et al. Electroacupuncture Delays Hypertension Development through Enhancing NO/NOS Activity in Spontaneously Hypertensive Rats. eCAM 2008; 1-6.
35. Beavers KM, Brinkley TE, Nicklas BJ. Effect of Exercise Training on Chronic Inflammation. Clinica Chimica Acta 2010; 411: 785-793.

36. Balducci S, Zanuso S, Nicolucci A, Fernando F, et al. Antiinflammatory Effect of Exercise Training in Subjects with type 2diabetes and the Metabolic Syndrome is dependent on Exercise Modalities and Independent of Weight Loss. Nutr Metab Cardiovas 2010; 20: 608617.

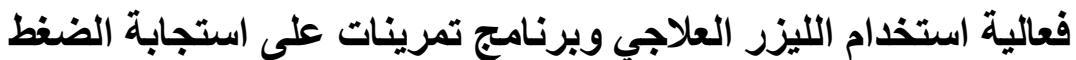 التأكسدي ومضادات التأكسد لاى مرضى ضغط الدام المرتفع البسيط الفيط}

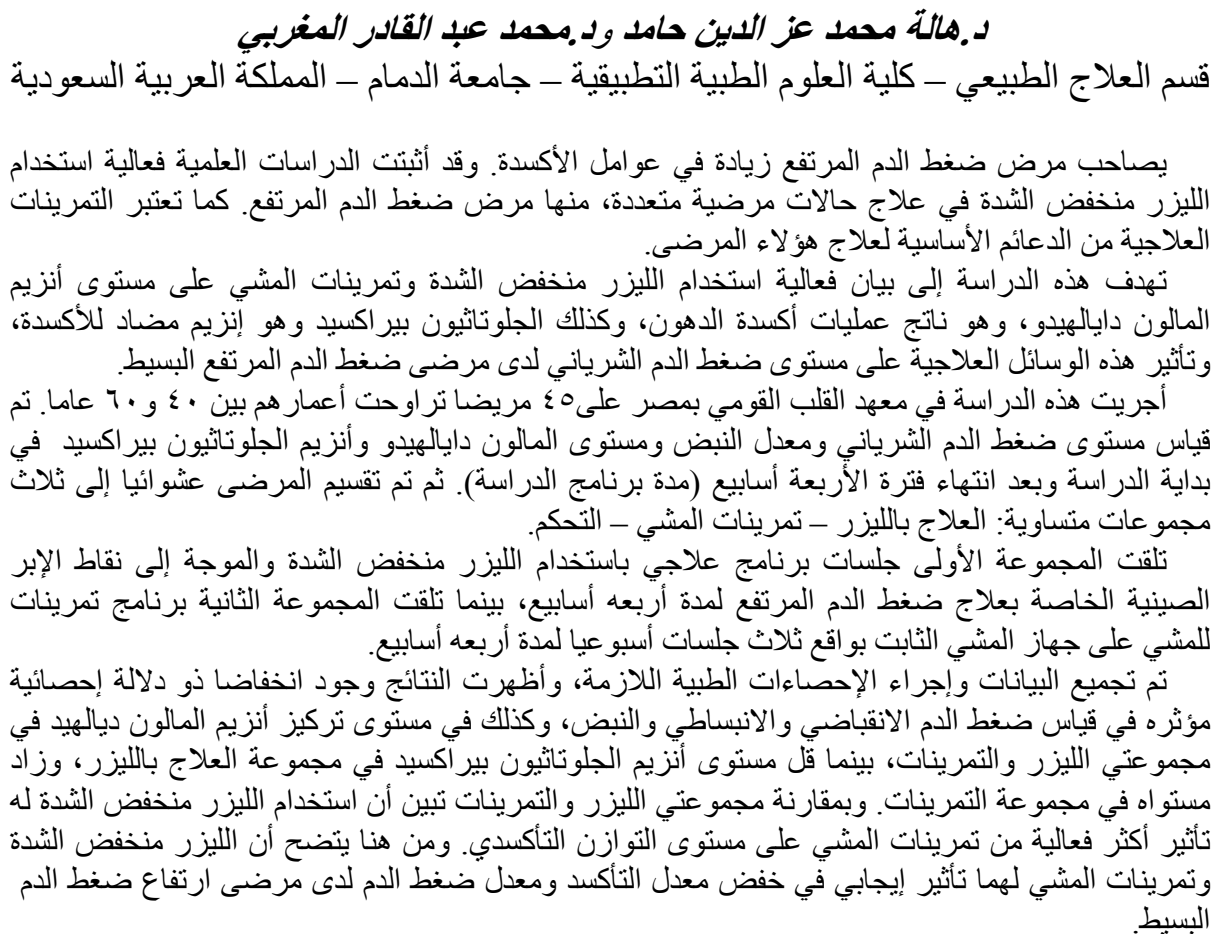

